\title{
Stitching Together: participatory textile making as an emerging methodological approach to research
}

\author{
Dr Emma Shercliff
}

Arts University Bournemouth, UK

\author{
Dr Amy Twigger Holroyd \\ Nottingham Trent University, UK
}

\begin{abstract}
Arising from a recently formed research network, Stitching Together, this article introduces a collection of case studies that critically examine participatory textile making as an emerging methodological approach to research. The twenty-first century resurgence of interest in textile processes such as knitting, sewing and weaving, whether as individual practice or community-based initiative, builds on a long and culturally diverse history of collaborative textile-making activity. This resurgence, combined with the familiarity, accessibility and flexibility of textile practices, has influenced a recent growth in the use of such activities as a means of inquiry within diverse research contexts.

The article considers the ways in which collective textile making projects privilege social encounter as a format for learning skills, creating friendships and consolidating shared interests. It goes on to discuss how researchers are drawing on these characteristics when devising new projects, highlighting the quality of experience afforded by textile making, the diverse forms of data generated and the variety of ways in which these participatory activities can be set up. Recognising that this research approach is far from straightforward, three key methodological themes are then considered: the multifaceted nature of the researcher's role and the complexities of relationships with participants and other stakeholders; the difficulties that can arise when using such familiar textile processes; and the opportunities, and complexities, of co-producing knowledge with participants through collaborative textile activity.
\end{abstract}

Keywords: textiles, craft, participatory textile making, research methodology, co-producing knowledge 


\section{Introduction}

The Bayeux Tapestry, an eleventh-century embroidery that recounts the Norman conquest of England across more than seventy metres of embroidered cloth, must be one of the most widely recognised examples of collective stitching effort. The American 'quilting bee', another well-known form of collaborative making which emerged in the early nineteenth century within colonial communities, brought people together to complete the making of patchwork bed quilts. Such archetypal examples of collective endeavour are referenced in later large-scale community-oriented textile initiatives, perhaps most notably the NAMES Project AIDS Memorial Quilt, which was conceived in 1985 by American AIDS activist Cleve Jones and now consists of over 48,000 stitched panels commemorating the lives of the many who have died of the syndrome. The resonance can also be felt in undertakings such as the Great Tapestry of Scotland, a vast community project completed in 2013 that was initiated by artist Andrew Crummy, writer Alexander McCall Smith and historian Alistair Moffat, and involved more than 1,000 volunteer stitchers, coordinated by Dorie Wilkie, from across Scotland.

Throughout these varied historical and cultural contexts, we can find people stitching together: such examples demonstrate that collective textile making is a well-established practice with a long history. The recruitment of many hands, brains and bodies to create a large textile spreads the load, enabling the creation of a complex, bulky or large-scale work that would be difficult, or even impossible, for an individual maker to manage alone. Likewise, people have long gathered together to work on smaller, individual textile projects; consider, for example, the groups which sprang up across Britain to knit items for troops during times of war and the contemporary equivalents which provide a convivial space for participants to knit for themselves or for charity. And since the internet has transformed the possibilities for social connection, geographically dispersed communities of contemporary makers are able to gain a sense of stitching together, despite their physical distance. 'Stitchalong' projects, for instance, involve multiple makers simultaneously following a single pattern, sharing practical tips and providing mutual support via an Instagram hashtag. Stitching with others in the twenty-first century cannot help but connect with a legacy of traditional stitching groups and practices that privilege social encounter and exchange as a format for learning new skills, creating friendships and consolidating shared interests.

An increase in specialist and general lifestyle magazines, television programmes, websites and blogs showcasing craft activities - alongside a broader resurgence of interest in craft and making - since the latter years of the twentieth century have contributed to a noticeable growth in community-based textile making projects. These projects may be self-organised by enthusiast groups, facilitated by cultural institutions or instigated by professional textile 
practitioners. In recent years, and accelerating in the past decade, we have seen this mode of practice shift into the realm of academic research. Today, research involving participatory textile making takes place in a wide range of disciplines, organised in diverse ways. This diversity means that participatory textile making cannot be framed as a single research method, but rather must be seen as a flexible approach which exploits the rich potential of making textiles with others as a means of inquiry. Yet to date there has been no forum for researchers using these activities to discuss their methodological and ethical decisions, successes and challenges. We founded the Stitching Together research network, which has been funded by the UK's Arts \& Humanities Research Council (AHRC) for two years from January 2019, to address this gap. The network aims to bring together researchers, practitioners and project commissioners with a shared interest in participatory textile making in order to generate improved critical understandings of this emerging methodological approach to research.

This issue, which is the first of a double special edition of the Journal of Arts and Communities, is a major output from the network's first year of activity. The call for papers demonstrated an intensity of activity that even we had not anticipated; submissions arrived from across the globe, far beyond the core UK-centric network membership. The eight papers published here present case studies of diverse projects which explore participatory textile making as a means, and sometimes the subject, of research; this diversity will be further expanded with the forthcoming companion issue. As we had hoped, the case studies highlight important methodological aspects of this work, including the complex and interrelated ethical and practical considerations involved in the undertaking of participatory textile projects. The case studies also introduce appropriate and relevant theoretical lenses that can be used to frame participatory textile making as research, and some demonstrate how established methodologies found in other research fields can be adapted to work within these new research contexts. Our hope is that this collection will be of use to researchers seeking to use participatory textile making in their own research, and to the network as we work to establish the validity and rigour of this approach. Thus, we see 'Stitching Together' as both literal and metaphorical: while the network is very much concerned with people making textiles together, it is also intended to act as a hub for a community of academics and makers to 'stitch together' a shared knowledge of this vibrant and fast-moving sphere of activity.

In this introductory article we will take a closer look at the 'person-oriented' characteristics of collective textile making projects; consider how researchers are drawing on these characteristics when devising new projects; and highlight some key themes that arise in this work. In addition to the case studies in this issue, we will make reference to the discussions 
and activities which unfolded at the network's first event, a two-day case study workshop involving thirteen researchers, in April 2019. This event set out to examine ways in which participatory textile making is being used as a new methodological approach to research and asked the attendees to share their participatory textile making activities in small group workshops (Figure 1). While the small number of participants inevitably limited the scope of discussion - and we readily acknowledge the problematic lack of gender and ethnic diversity in the group - the collaborative and activity-based nature of the workshops gave space for us to start a conversation about our experiences, teasing out the characteristics of each activity and identifying key methodological themes.

[insert Figure 1 here]

\section{'Person-oriented' making activities}

It is worth noting at this early juncture that, as coordinators of the Stitching Together network, our view of 'stitching together' is purposely inclusive. Thus, in addition to the various examples of collective textile making outlined above, we choose to embrace studies in which participants contribute to the collaborative creation of textile items through discussion and consultation, though without direct involvement in any physical stitching, such as the Emotional Fit project led by network member Katherine Townsend (Townsend, Sissons \& Sadkowska, 2017). Our scope even extends to the fascinating work of Marion Lean, another member of the network, whose doctoral research uses haptic engagement with textile materials to explore the affective and sensory dimensions of data (Lean, 2019). Similarly, we readily embrace the experience of network member Katie Gaudion, whose research workshops with carers of autistic adults are developed from experiments in handling a wide range of materials, as well as textiles, to make sensory props (Gaudion, 2015). Furthermore, we recognise those participatory textile making initiatives where the social 'togetherness' occurs solely online, as in the research discussed by Alison Mayne in this issue.

For now, though, we will step back to those archetypal settings we mentioned at the start of the article, in which many hands are involved in the making of labour-intensive textile creations. Projects of this type are examined in detail within this issue: Linda Claire Warner, Pirita Seitemaa-Hakkarainen and Kai Hakkarainen discuss a case study of a collaborative quilting project in Aotearoa, New Zealand, while Sarah Brown and Stephanie Bunn provide accounts of apprenticeships within the very different traditions of Malagasy mat-weaving and Kyrgyz felt-making, respectively. As a form of creative practice, making textiles together in a 
group places emphasis on the connections and interactions between people: it is a 'personoriented' approach to craft as work that cherishes people, rather than objects (Freeman, 1997). Sewing or knitting are ideal communal stitch-crafts: they occupy the hands in a sufficiently detailed and precise task to require the focused attention for productive activity, but with short and repeatable bursts of activity which allow for moments of distraction. Furthermore, this dynamic allows participants to customise their experience. Participation in a lively shared conversation or activity can typically be exchanged for quiet concentration, isolated contemplation and a sense of self-reliance (Shercliff, 2015a).

The ubiquity of textile making across cultures makes it a convenient platform for addressing various aspects of self-development and social inclusion. The social format of stitching groups brings together individuals who might otherwise find social activities and educational opportunities hard to access because of cultural, age or language barriers. Joining a group may help to address social and personal concerns affecting individuals alienated by unemployment or separation from family networks. These concerns can be articulated empathetically through the mutual sharing of such experiences, filtered through the making activities. The work undertaken by The Social Studio, a social enterprise based in Melbourne, Australia, fits this description and is discussed in this issue by Grace McQuilten, its founder, and Amy Spiers. These kinds of collective stitching projects help participants to 'make' sense of their experiences in ways described by artist Françoise Dupré:

[A] meaningful and ethical collaborative-participatory practice is one that engages with participants' identity, taps into their experience and history and provides a context for participants to become active social subjects. Integral to the process is the production of some kind of tangible object where individuals and community can, through the making and experiencing of the object's physicality and materiality, translate emotions, desires and experiences, create new meanings and shape their identity. (Dupré, 2008: 3).

The 'stitching together' here embodies a function of care and attention to individuals' experiences within their larger social networks.

The transformative values described above also make use of the therapeutic benefits of textile crafting. Much has been written about how the quiet, meditative rhythms of stitching and knitting can provide a focused activity of manageable proportions in times of insecurity and offer solace in times of distress (Corkhill et al., 2014). While textile making does not often provide instantly gratifying results, it can offer moments of calm for introspective reflection (Hackney, Maughan \& Desmarais, 2016). For some, the accumulation of stitches, visibly recording a forward progression through time, contributes positively to a healing 
process (Turney, 2007). Interestingly, whilst it is common to discuss the restorative benefits of textile crafting for the maker, Juliette MacDonald and Andrea Peach offer an alternative perspective in their article for this issue, presenting a case for the benefits to recipients of hand-crafted gifts in the form of knitted breast prosthetics, made by a network of knitters. In their case study, the material sensations of soft, pliable yarn at body temperature help to convey a sense of emotional and physical care that bypasses the more conventional reconstructive surgical interventions.

The 'knitted knockers' discussed by Peach and MacDonald subtly and cleverly subvert normative ideas around women's bodies, an approach that owes much to the 1970s and 1980s feminist retrieval of domestic crafts such as knitting and embroidery to address political and social injustices. ${ }^{1}$ Indeed, the political power of collectively made textiles is an important legacy of the feminist movement. Consider the suffragette banners made by regional groups for the Women's Social and Political Union (WSPU) marches in the early twentieth century, and more recent iterations such as the knitted petition against the exploitation of garment workers by Nike, coordinated by activist artist Cat Mazza, and of course, the mass making and wearing of hand-knitted pink 'pussy hats' in solidarity for women's rights. The impact and effectiveness of these works draws from the traditions of gathering people together to enable the making of large-scale textiles mentioned earlier. In this mould, with varied degrees of political or personal activism, stitching groups continue to represent ideas of community and identity, from 'The Knitting Map' of Cork, Ireland (Gilson \& Moffat, 2019) to the Dorcas Clubs serving Caribbean migrant communities (Sinclair, 2015). Fiona Hackney and colleagues develop these themes of 'quiet activism' further in their article for this issue. In the context of raising awareness of sustainable fashion, they consider how an embodied and affective engagement with making textiles together can influence a change in people's views about their clothing choices.

\section{Move into research}

In recent years, participatory textile making has increasingly featured in research activities as both the subject of inquiry and the means of investigation - and, in some instances, also as a way of communicating the research. This development can partly be traced to the growth of doctoral studies in art and design and the desire of practice-based researchers to draw on their skills in both making and facilitation. This is the case for both of us: we have professional experience as textile practitioners and workshop facilitators, which led us into our PhD projects and subsequent academic roles. Emma's doctoral research explored the correlation between the practical skills of hand-stitching and the crafting of mutuality and 
cooperation in group making activities (Shercliff, 2015b), while Amy investigated the lived experience of making and wearing homemade clothes through a participatory exploration of remaking knitted garments (Twigger Holroyd, 2013). We have continued to use participatory textile making activities within our various postdoctoral research projects (Figures 2 and 3 ). Yet the projects discussed in this issue - along with those undertaken by other members of the Stitching Together network - demonstrate that textile making activities are being used far beyond the art and design context, and by researchers without university-level textile education or professional experience. The network has discovered participatory textile making activities being used in varied contexts across a range of disciplines, from occupational therapy and human computer interaction to community building and sustainable development, to gain rich insights into questions of artistic, scientific, social, material and cultural value.

[insert Figures 2 and 3 here]

What can account for this diversity and extent of activity? The accessibility and flexibility of textile making processes such as knitting, sewing and weaving, as mentioned above, must be key factors. Stitch-crafts are familiar within many social and cultural contexts; even where such processes are not fully embedded in the day-to-day life of a community, their popularity means that participants are often strongly motivated to take part. Projects can often be set up in such a way that participants do not need to have specialist expertise in order to join in, and opportunities to learn can be offered on site. Readily available tools and materials, combined with easily transportable projects, mean the work can be flexibly slotted in around other tasks or events. Turning "technical competence into sociable experience" (Sennett, 2012: 63), opportunities for building confidence, meeting others, and learning new skills are presented to participants as they join in a making project.

A few years ago, at the outset of our Stitching Together collaboration, we compared practical aspects of the textile making activities we had each pursued and found great variety even within our two doctoral projects (Shercliff and Twigger Holroyd, 2016). Contributors to this special edition similarly demonstrate the diversity of participatory making research initiatives. In terms of project formats, for example, a drop-in 'have a go' setup forms the basis of Rosa Tolnov Clausen's Weaving Kiosk, while Linda Claire Warner, Pirita Seitemaa-Hakkarainen and Kai Hakkarainen profile a group of already skilled participants undertaking a tightly focused, task-driven weekend workshop. The examples we have gathered through the network's activities and within this issue readily demonstrate that textile making projects are 
endlessly variable - from the functional to the expressive, the speculative to the necessary, and the personalised and individual to the communal and collective.

Another important factor in the growth of participatory textile making in research is the quality of the experience afforded by textile making. The slow pace of hands-on making in the company of other people - as discussed above - creates space for rich shared experiences such as the learning of new skills or new understandings of habitual experiences; a gentle exploration of difficult-to-raise topics; a ready opportunity to communicate with others, or even quiet contemplation. Diverse forms of data can be generated through these activities - visual, tactile, textual, oral, aural, emotional, experiential and temporal - allowing the researcher to draw on much more than words alone.

Furthermore, gathering data during the making activity means that connections between doing, thinking and talking can be captured simultaneously. This enables researchers to access the knowledge that emerges 'in the moment' of making, and can reveal changes in perception which occur during the process. It is worth noting that the relative intimacy provided by textile making seems to help people to open up, allowing the research to reach sensitively into corners of human experiences that other methods, such as interviewing, may struggle to access. Discussions at the first network event highlighted this 'opening up' as a characteristic shared across many diverse projects, to the extent that researchers must consider the ethical dimensions of managing such information. Sarah Brown summarises this challenge eloquently in her article for this issue: 'Trust was built, and participants often used the space to tell such deeply personal stories that at times I questioned the ethics of using a method that seemed so potent.'

Along with the various productive attributes of research activities involving participatory textile making discussed here, our work has also identified problems which are frequently associated with their use. The everyday familiarity which gives textiles such a wide reach can mean that textile making activities are not always designed into research initiatives with methodological rigour in mind. It can also mean that they are taken for granted or even treated as a frivolity, rather than being given due attention as a valid means of research. Furthermore, finding ways to document, analyse, articulate and disseminate the kinds of knowledge practised in participatory textile making activities presents complex practical and methodological challenges. And while positive outcomes for participants in participatory textile projects are often observed by researchers, Price (2015) argues for greater critical examination of the impacts that these approaches have on participants. We discussed these problems and complexities when we ran the first network workshop; below, we share three important themes which emerged from our conversations. 


\section{Relationships and roles}

As might be expected, relationships with participants featured prominently in our discussions. We have previously highlighted the fact that the researcher's role is often multifaceted, involving the need to simultaneously act as facilitator, instructor, host, maker and/or participant (Shercliff \& Twigger Holroyd, 2016). Occupying these multiple roles while responding sensitively to the needs of those involved is not only potentially exhausting; it can also complicate researcher-participant relationships. While there are strategies that can be employed to address these issues, each strategy carries its own challenges. For example, video recording can be a valuable asset, creating a visual document to be studied after the event and even revealing detail missed during the sessions. Yet recording can obstruct the creation of an open and trusting atmosphere. Similarly, bringing in additional people to assist with documentation or instruction can lighten the load on the researcher, but may alter the interpersonal dynamics in the space. Multi-disciplinary research teams for larger projects, such as the one described by Fiona Hackney and colleagues in their case study article, bring a valuable mix of skills and expertise - but also another layer of complexity in terms of planning and management.

The network event in April 2019, at which researchers shared their first-hand experiences of running participatory textile activities, brought to light another type of relationship: that between a researcher and a partner organisation or funder. For example, a researcher may partner with a local charity to work with a pre-existing group of participants, or with a specialist organisation to gain access to participants with specific expertise or interests. Such stakeholders have different priorities, which - along with the priorities of the participants - need to be taken into account by the researcher in the design of the project. This can lead to a demanding three-way balancing act: maintaining research integrity while also meeting the expectations of partner organisations and respecting the needs of participants.

Relationships between researcher, participants and other stakeholders are shaped by the format of the project or making activity - from fleeting experiences to regular meetings of skilled and experienced participants over months, or even years, as is the situation in Sarah Brown's case study. The existence, or lack, of relationships between participants at the outset of the project can further influence the way in which a project unfolds. Another factor is the environment within which workshops take place; consider, for example, the difference between workshops which bring participants into the textile studios of an art school and ethnographic projects which take the researcher to an unfamiliar cultural context. Rosa Tolnov Clausen's article in this issue provides a fascinating examination of the dynamics at play when a researcher invites participants into a space they have created, introducing the 
useful concept of 'having visits' as a theoretical lens through which to consider the researcher's role as 'host'.

\section{The textile making}

We have discussed how the familiarity of textile materials and processes lends itself to a way of doing research that has the potential to explore the richness and depth of diverse experiences. The activity of making occupies the mind, body and senses in a subtly dynamic engagement with materials and place and prompts unforeseen connections that cannot necessarily be put into words eloquently; a full understanding of the meaning embedded within the conversation that might take place necessitates immersion in the making process. Grace McQuilten and Amy Spiers highlight this point in their article: 'we weren't able to rely on language and structured questioning to generate our research data - instead we negotiated our own manual and creative skills and came into a closer exchange of practice with ... staff and students'. Here the researchers' knowledge of participatory making generally and specialist textile making skills in particular played an important role. We might consider whether a researcher who did not have such skills would have been able connect with the intangible and unspoken experiences of project participants.

Although we have emphasised the many benefits associated with the ubiquity and broad appeal of textiles, it is important to note that textile making is not a universally pleasurable activity. While a textile making activity may be set up to facilitate unstructured participation through playful experimentation with techniques and materials, this could be an uncomfortable experience for some. A lack of clear instruction can feel disorienting and places pressure on people to make decisions for which they are unprepared. Similarly, an inclusive 'have a go' experience could inadvertently put off skilled participants who feel that their knowledge and prior experience are not valued or respected. In other situations, the skills of the makers could form the basis of the research project, as is the case with the network of knitters discussed by MacDonald and Peach: highly skilled hand knitters are recruited to make the 'knitted knockers' through a stringent application process. An open invitation to participate in a textile making project means the prior experience, skill level or aesthetic sensibility the participants bring with them can never quite be known. Therefore, it is important to challenge any expectation that the making will automatically be a joyful, expressive experience for participants. We should also be alert to issues of authority and power which may be lurking beneath the surface of an ostensibly inclusive project; for example, in collective textile making initiatives conceived with a desire for aesthetic unity, there arises the difficult question of who decides what kind of stitching is acceptable. 
The participatory workshop as an approach holds great potential to introduce people to new experiences and transform lives, but conversely can also heighten entrenched positions. The ubiquitous familiarity of textile making also brings expectations grown from prior knowledge that can be difficult to transgress or subvert. These expectations anchor around ideas of what constitutes 'good' work and worthwhile effort, cultural specificities regarding technique and aesthetics, and of course, the female gendered dominance of textile making. In their case study, McQuilten and Spiers - working with people from refugee and migrant backgrounds - draw our attention to a non-Western context and offer a welcome challenge to the westernised lens through which we habitually discuss textile making and its relationship to gender.

\section{(Co)-production of knowledge}

Whether participatory textile making projects are embedded within an existing group of people or create new temporary groups of like-minded practitioners, these activities have the capacity to create community, and therefore lend themselves to various dynamic fields of study as witnessed by the range of articles presented in this special edition. The relevance of these projects to all sorts of people can reveal many layers of meaning and therefore many levels of possible interpretation. Researcher, participants, project commissioners and audiences may interpret the making process and the work created differently, and would likely take differing views on the nature of the knowledge being created. This raises a question about whose interpretation is privileged through documentation and dissemination. It could be argued that the format of participatory making projects helps to challenge this issue of privilege; the slowness of textile activities typically creates space for the researcher to reflect while simultaneously concentrating on the phenomena at hand, thus facilitating a fluid exchange of learning between researcher and participants and challenging implicit hierarchies. For example, McQuilten and Spiers discuss how their engagement as researchers in the weaving workshop led by a participant allowed them to gain a different perspective on the learning of skills within this context, bringing 'researchers and subjects into a more equal exchange'. In her article, Alison Mayne reminds us that online spaces can extend access for communities, reaching further afield than is possible for researchers in physical locations. In addition to this advantage, Mayne argues that online spaces should also be considered as valuable opportunities for collaborative reflection, with both researcher and participants using the pause required to compose and upload information to a digital platform to consider and distill their ideas. Stephanie Bunn, in her article, proposes that we should consider such collaborative exchanges as cumulative, benefitting 
researchers and communities alike as they take us to the boundaries of what we know, sometimes affecting and informing us in unanticipated ways. We might therefore describe participatory textile making contexts - or some of them, at least - as communities of practice that facilitate the co-production of knowledge. Yet with the co-production of knowledge comes a responsibility to tell the stories of participation respectfully - a responsibility that, once again, raises many questions about authority, aesthetics and ownership.

We will pick up this question of respectful communication, along with other ethical dimensions of participatory textile research activity, in our introduction to the second part of this double issue. We will draw on the second network event, a critical reflection workshop involving researchers, professional textile practitioners, project commissioners and critical friends which took place in July 2019 , and which aimed to investigate the issues raised by these new methodological approaches for the validity and effectiveness of the research. Such an investigation is crucial as we look to the future and seek to grow, diversify and strengthen this highly productive, yet frequently complex, approach to research.

\section{Acknowledgements}

'Stitching Together' is funded by a research networking grant from the Arts and Humanities Research Council: grant reference AH/R007497/1.

Our grateful thanks to all the participants at the first Stitching Together networking event held in April 2019:

Dr Stephanie Bunn, Dr Rebecca Collins, Dr Sarah Desmarais, Sarah Green, Professor Fiona Hackney, Katie Hill, Marion Lean, Dr Alison Mayne, Dr Lynn Setterington, Dr Nicola Thomas, Professor Janet Van Der Linden.

\section{References}

Buszek, M. E. (2011) (ed.), Extra/Ordinary Craft: Craft and Contemporary Art, Durham, NC: Duke University Press.

Corkhill, B., Hemmings, J., Maddock, A. \& Riley, J. (2014), 'Knitting and Well-being', Textile, 12:1, pp. 34-57, DOI: 10.2752/175183514×13916051793433.

Dupré, F. (2008), 'Making Stuff', Axis Dialogue, http://axiswebmedia.blob.core.windows.net/www/usermedia/103684/work/204094/vvwxlsvou ggj46xenikhw.pdf. Accessed 29 February 2020. 
Freeman, J. (1997), 'Revering things or cherishing people: some professional and popular approaches to constructing craft communities', in: T. Harrod (ed.) Obscure Objects of Desire: Reviewing the Crafts in the Twentieth Century, University of East Anglia, 10-12 January 1997, London: Crafts Council, pp. 267-274.

Gaudion, K., Hall, A., Myerson, J. \& Pellicano, L. (2015), 'A designer's approach: how can autistic adults with learning disabilities be involved in the design process?', CoDesign, 11:1, pp. 49-69, DOI: 10.1080/15710882.2014.997829.

Gilson, J. \& Moffat, N. (2019) (eds.), Textiles, Community and Controversy: The Knitting Map, London: Bloomsbury.

Hackney, F., Maughan, H. \& Desmarais, S. (2016), 'The Power of Quiet: Re-making Affective Amateur and Professional Textiles Agencies', Journal of Textile Design Research and Practice, 4:1, pp. 33-62, DOI: 10.1080/20511787.2016.1256139.

Lean, M. (2019), 'Designing the Affective Material Palette. Using materials to explore the experience of systems and technologies designed to aid behaviour change', The Design Journal, 22:sup1, pp. 2177-2178, DOI: 10.1080/14606925.2019.1595462.

Parker, R. (2010), The Subversive Stitch: Embroidery and the Making of the Feminine, London: I.B Tauris.

Price, J. (2015), 'Contesting agendas of participation in the arts', Journal of Arts \& Communities, 7:1+2, pp. 17-31, DOI: 10.1386/jaac.7.1-2.17_1.

Robertson, K. \& Vinebaum, L. (2016) (eds.) ‘Crafting Community’, Textile, 14:1, pp. 2-13. Sennett, R. (2012), Together: The Rituals, Pleasures and Politics of Cooperation, London: Yale University Press.

Shercliff, E. (2015a) Joining In and Dropping Out: hand-stitching in spaces of social interaction. Craft Research. Vol. 6.2. pp. 187-207. DOI: 10.1386/crre.6.2.187_1

Shercliff, E. (2015b) 'Articulating Stitch: skilful hand-stitching as personal, social and cultural experience', PhD thesis, London: Royal College of Art.

Shercliff, E. \& Twigger Holroyd, A. (2016) Making With Others: working with textile craft groups as a means of research. Studies in Material Thinking. [online]. Vol. 14.

Sinclair, R. (2015), 'Dorcas legacies, Dorcas futures: Textile legacies and the formation of identities in 'habitus' spaces', Craft Research, 6: 2, pp. 209-222, DOI:

10.1386/crre.6.2.209_1. 
Townsend, K., Sissons, J. \& Sadkowska, A. (2017), 'Emotional Fit: Developing a new fashion methodology with older women', Clothing Cultures, 4:3, pp. 235-251, DOI: 10.1386/cc.4.3.235_1.

Turney, J. (2007), 'Releasing the tension: making meaning through mindful knitting' in: Follet, G. \& Valentine, L. (eds.) New Craft - Future Voices, International Conference \& Exhibition, Duncan of Jordanstone College of Art \& Design, University of Dundee, Scotland, 4-6 July 2007, pp. 248-255.

Twigger Holroyd, A. (2013), 'Folk Fashion: amateur re-knitting as a strategy for sustainability', $\mathrm{PhD}$ thesis, Birmingham City University.

\section{Bio}

Dr Emma Shercliff is a stitcher, researcher and writer who has been involved with creative, community-based textile-making activities as both workshop leader and participant for over 20 years. She is a Senior Lecturer in Textiles at the Arts University Bournemouth. Her doctoral research explored the relationship between the rhythms and patterns of skilful hand-stitching processes and the crafting of mutuality and cooperation practised in collective making. Emma continues to explore the impact and value of creative and collaborative making and drawing workshops as tools for doing research.

Dr Amy Twigger Holroyd is a designer, maker, researcher and writer who has explored the emerging field of fashion and sustainability since 2004. She is an Associate Professor at Nottingham Trent University. Amy's doctoral research, which investigated the lived experience of making clothes at home and the reworking of knitted garments, led to a monograph, Folk Fashion: Understanding Homemade Clothes, and solo exhibition, Units of Possibility: The Reknit Revolution. Amy's latest work aims to imagine, prototype and analyse enticing alternative fashion worlds through a playful and collaborative design process.

\footnotetext{
${ }^{1}$ Much has been written about the making of textile crafts as gendered activities and their relationship to feminist informed politics. See in particular Rozsika Parker's seminal text The Subversive Stitch: embroidery and the making of the feminine (2010); for a conceptual harnessing of textile craft making in contemporary art contexts including activism, see Maria Elena Buszek Extra/Ordinary Craft: craft and contemporary art (2011); and for the power of collective textile making as communal voice, see the 'Crafting Community' special issue of Textile: the Journal of Cloth and Culture, vol. 14, issue 1, edited by Kirsty Robertson and Lise Vinebaum (2016). However, building on this excellent work, our focus here is methodological.
} 